\title{
Preparation of Nano-Modified Polyacrylamide and Its Application on Solid-Liquid Separation in Waste Drilling Mud
}

\author{
Fanghui Wang, Jiantao Fan, Hong Zhu', Kefei Han, Jing Zou, Haiyun Sun \\ Institute of Modern Catalyst, State key Laboratory f Chemical Resource Engineering, School of Science, \\ Beijing University of Chemical Technology, Beijing, China \\ E-mail: fhwang@mail.buct.edu.cn \\ Received December 13, 2010; revised January 10, 2011; accepted March 30, 2011
}

\begin{abstract}
To satisfy the requirement on solid-liquid separation in high-density waste drilling mud, prepare the nano-modified polyacrylamide (PAM) flocculant for high density waste drilling mud by in-situ dispersion method, direct dispersion method and simultaneous formation method. The result showed the flocculent effect of nano-modified polyacrylamide prepared by simultaneous formation method was the best. When the content of water glass and acrylamide (AM) were respectively $3 \%$ and $15 \%$, reaction temperature was $60^{\circ} \mathrm{C}$ and reaction time was $3 \mathrm{~h}$, the performance of product was the best. The water content in filter cake was $24.32 \%$ after the waste drilling mud disposed by the optimization flocculant. The flocculent effect of optimization flocculant was superior to that of other flocculant in market.
\end{abstract}

Keywords: In-Situ Dispersion Method, Direct Dispersion Method, Simultaneous Formation Method, Nano-Modified Polyacrylamide, High Density Waste Drilling Mud

\section{Introduction}

The waste drilling fluids was the inevitable industrial waste while Oil and Gas exploration drilling. It had become one of the most severe pollution sources, whose effect on environment has been concerned gradually [1-3]. There were many methods [4-6] to dispose the waste drilling mud and drilling wastewater. The solidliquid separation [7] was the most important and widely application method. At deep well drilling, the component of waste drilling mud was complexity, the density of waste drilling mud was higher and higher, and the waste drilling mud treatment was more and more hard [8]. The flocculant in market had not deal with the high density waste drilling mud. So a new nano-modified polyacrylamide flocculant for high density waste drilling mud was prepared.

\section{Experiment}

\subsection{Agent}

Cation polyacrylamide (GP), anion polyacrylamide (GP), silane coupling agent KH570 (GP), homemade nano$\mathrm{SiO}_{2}(40-60 \mathrm{~nm}$ ), water class (modulus $=3.2 \sim 2.3$ ), hydrochloric acid (AR), absolute ethyl alcohol (AR), acrylamide (AR), Potassium peroxydisulfate (AR), Sodium sulfite (AR), oxalic acid (AR), Nitrogen.

High density waste drilling mud, the density is $1.639 \mathrm{~g} / \mathrm{mL}$ and the solid content is $56.72 \%$.

\subsection{Preaparation of Nano-Modified Polyacrylamide}

\subsubsection{In-Situ Dispersion Method}

(1) Preaparation of nano-modified Cation polyacrylamide (CPAM)

Dissolve respectively $4.2 \mathrm{~g} \mathrm{Na}_{2} \mathrm{SiO}_{3}$ in $10 \mathrm{ml}$ deionized water and $8.0 \mathrm{~g}$ CPAM in $380 \mathrm{ml}$ deionized water, then drop the $\mathrm{Na}_{2} \mathrm{SiO}_{3}$ solution into CPAM solution and mix equably. Make $\mathrm{HCl}$ to adjust the $\mathrm{pH}$ of above mixture to about 7 and keep the system react for $3 \mathrm{~h}$ at room temperature.

(2) Preaparation of nano-modified anion polyacrylamide (APAM)

Dissolve respectively $4.2 \mathrm{~g} \mathrm{Na}_{2} \mathrm{SiO}_{3}$ in $10 \mathrm{ml}$ deio- 
nized water and $8.0 \mathrm{~g}$ APAM in $380 \mathrm{ml}$ deionized water, then drop the $\mathrm{Na}_{2} \mathrm{SiO}_{3}$ solution into APAM solution and mix equably. Make $\mathrm{HCl}$ to adjust the $\mathrm{pH}$ of above mixture to about 7 and keep the system react for $3 \mathrm{~h}$ at room temperature.

\subsubsection{Direct Dispersion Method}

Disperse 8.0 g homemade nano $\mathrm{SiO}_{2}$ in $50 \mathrm{ml}$ absolute ethyl alcohol, add $2 \mathrm{ml} \mathrm{KH570}$ into above mixture, then keep stirring and reacting for $48 \mathrm{~h}$ at room temperature. Drying above mixture in the end at $60^{\circ} \mathrm{C}$ to gain the nano $\mathrm{SiO}_{2}$ modified by silane coupling agent. Disperse $4.0 \mathrm{~g}$ nano $\mathrm{SiO}_{2}$ modified by silane coupling agent in $100 \mathrm{ml}$ deionized water, add $5 \mathrm{~g}$ acrylamide into above mixture and removal of oxygen dissolved in the solution by blowing continuously nitrogen. Then add $0.1 \mathrm{~g}$ potassium persulfate to initiate polymerization and keep the system react for $4 \mathrm{~h}$ to gain product.

\subsubsection{Simultaneous Formation Method}

Dissolve $4 \mathrm{ml}$ water class into $80 \mathrm{ml}$ deionized water, adjust the $\mathrm{pH}$ of the water class solution to $3-4$ by $\mathrm{HCl}$ and react for $1 \mathrm{~h}$ at room temperature. Dissolve $1 \mathrm{ml}$ KH570 into $10 \mathrm{ml}$ absolute ethyl alcohol, adjust the $\mathrm{pH}$ of the KH570 solution to 3 by oxalic acid and hydrolyze for $1 \mathrm{~h}$ at room temperature. Add KH570 solution into water class solution, then add 20 acrylamide into above mixture and removal of oxygen dissolved in the solution by blowing continuously nitrogen. Finally add $0.1 \mathrm{~g}$ potassium persulfate and $0.1 \mathrm{~g}$ sodium sulfite into above system to initiate polymerization. Keep the system react for $4 \mathrm{~h}$ to gain product.

\subsubsection{Flocculent Treatment}

Add $4 \mathrm{ml} \mathrm{MgCl}_{2}$ solution $(0.2 \mathrm{~g} / \mathrm{ml})$ as gel breaker to 200 $\mathrm{g}$ waste drilling mud (1:1-fold diluted with water), then add some flocculant to above system and stir, centrifugal separation (4000 r/min) for $10 \mathrm{~min}$. Weight the quality of filter cake (m1) and soild phase after baking (m2). Gain the water content in filter cake by the formula as follows:

The water content in filter cake $=(\mathrm{m} 1-\mathrm{m} 2) / \mathrm{ml}$.

\section{Result and Discussion}

\subsection{Flocculent Effect of Three Kinds of Preparation Method}

(1) Nano-modified CPAM flocculant prepared by in-situ dispersion method

(2) nano-modified APAM flocculant prepared by in-situ dispersion method

(3) nano-modified PAM flocculant prepared by direct dispersion method

(4) nano-modified PAM flocculant prepared by simul- taneous formation method

From Tables 1-4, we can know that flocculent effect of nano-modified polyacrylamide prepared by simultaneous formation method was the best Among three preparation methods. The optimum conditions for preparing nanomodified polyacrylamide prepared by simultaneous formation method was obtained through orthogonal experiments.

\subsection{Optimization of the Simultaneous Formation Method}

Content of water class and acrylamide, react temperature and react time were selected and tested by four-factorsthree-level orthogonal processing test. The test result is shown in Table 5.

From Table 5, we can know the test number 2 was the best.

\subsection{Analysis of FTIR}

Figure 1 was The FTIR spectrum of the sample (test number 2 in Table 5). As can be seen from the Figure 1, the peak of IR spectra of N-H stretching vibration appeared at $3419 \mathrm{~cm}^{-1}$ and $3197 \mathrm{~cm}^{-1}$; the peak of IR spectra of $-\mathrm{CH}_{2-}$ asymmetry stretching vibration and $-\mathrm{CH}_{2-}$ symmetric stretching vibration appeared respectively at $2922 \mathrm{~cm}^{-1}$ and $2850 \mathrm{~cm}^{-1}$; the absorption peak appeared at $1652 \mathrm{~cm}^{-1}$ and $1417 \mathrm{~cm}^{-1}$ was caused respectively by the stretching vibration of $\mathrm{C}=\mathrm{O}$ in acylamide group and vibration of saturated $\mathrm{C}-\mathrm{H}$. The absorption peak of $\mathrm{Si}-\mathrm{O}-\mathrm{C}$ and $\mathrm{Si}-\mathrm{O}-\mathrm{Si}$ appeared at $1120 \mathrm{~cm}^{-1}$.

Table 1. The effect of Content of nano-modified CPAM on the water content in filter cake.

\begin{tabular}{ccccc}
\hline Content of flocculant (\%) & 0.2 & 0.4 & 0.6 & 0.8 \\
\hline The water content in filter cake (\%) & 51.05 & 52.30 & 46.04 & 47.62 \\
\hline
\end{tabular}

Table 2. The effect of Content of nano-modified APAM on the water content in filter cake.

\begin{tabular}{ccccc}
\hline Content of flocculant (\%) & 0.2 & 0.4 & 0.6 & 0.8 \\
\hline The water content in filter cake (\%) & 56.37 & 54.47 & 48.76 & 50.07 \\
\hline
\end{tabular}

Table 3. The effect of Content of flocculant on the water content in filter cake.

\begin{tabular}{ccccc}
\hline Content of flocculant $(\%)$ & 0.2 & 0.4 & 0.6 & 0.8 \\
\hline The water content in filter cake (\%) & 35.98 & 35.24 & 34.87 & 35.13 \\
\hline
\end{tabular}

Table 4. The effect of Content of flocculant on the water content in filter cake.

\begin{tabular}{ccccc}
\hline Content of flocculant (\%) & 0.2 & 0.4 & 0.6 & 0.8 \\
\hline The water content in filter cake (\%) & 33.01 & 32.55 & 30.68 & 31.73 \\
\hline
\end{tabular}


Table 5. The test result of orthogonal experiment.

\begin{tabular}{|c|c|c|c|c|c|}
\hline Test number & $\begin{array}{c}\text { Content of } \\
\text { water class } / \%\end{array}$ & $\begin{array}{c}\text { Content of } \\
\text { acrylamide/\% }\end{array}$ & React temperaturee $/{ }^{\circ} \mathrm{C}$ & React time/h & the water content in filter cake/\% \\
\hline 1 & 3 & 10 & 50 & 2 & 30.23 \\
\hline 2 & 3 & 15 & 60 & 3 & 24.32 \\
\hline 3 & 3 & 20 & 70 & 4 & 25.98 \\
\hline 4 & 5 & 10 & 60 & 4 & 26.67 \\
\hline 5 & 5 & 15 & 70 & 2 & 25.49 \\
\hline 6 & 5 & 20 & 50 & 3 & 26.35 \\
\hline 7 & 7 & 10 & 70 & 3 & 26.22 \\
\hline 8 & 7 & 15 & 50 & 4 & 28.38 \\
\hline 9 & 7 & 20 & 60 & 2 & 29.89 \\
\hline
\end{tabular}

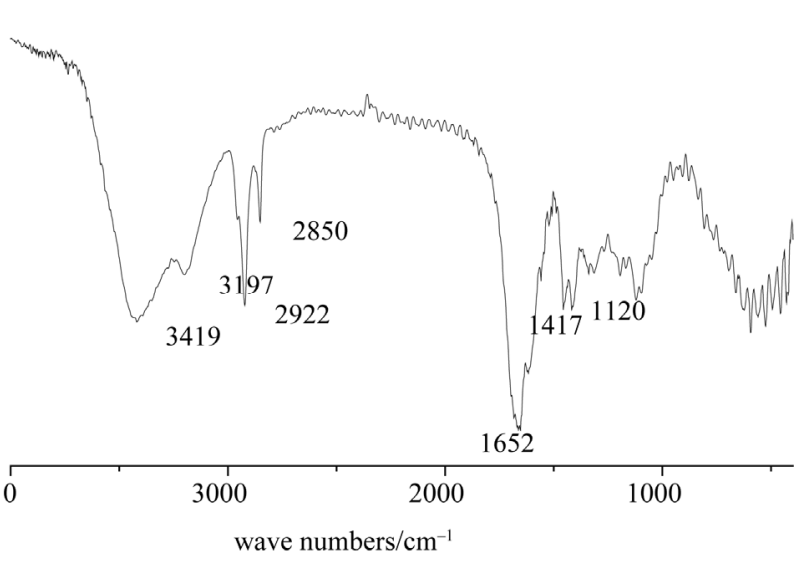

Figure 1. The FTIR spectrum of the nano-modified PAM flocculant.

So, we can think that there must have some structural units of $\mathrm{AM}$ and $\mathrm{SiO}_{2}$ in the nano-modified flocculant.

\subsection{Contrast of Flocculent Effect}

We contrast the flocculent effect of nano-modified flocculant prepared by simultaneous formation method with that of the other coagulant in matket, such as, Non-ionic polyacrylamide, cationic polyacrylamide, anionic polyacrylamide, polymerization ferric sulphate, Polymerization aluminum sulfate, nano-modified flocculant.

From Figure 2 we can see that adding the same amount of flocculant, the flocculent effect of organic flocculants was better than that of inorganic coagulant, but the results were not satisfactory, the water content in filter cake $\geq 50 \%$. The flocculent effect of the nano-modified flocculant is significantly better than that of the other coagulant in matket, water content of waste drilling mud after treated is $24.32 \%$.

\section{Conclusions}

Water class and acrylamide used as raw matierial and potassium persulfate as initiator to prepare nano-

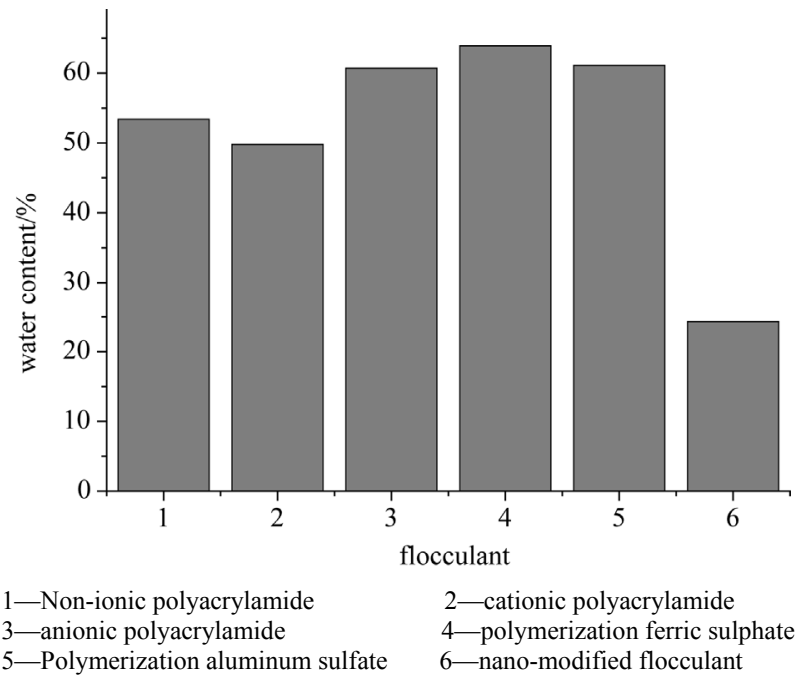

Figure 2. Floccuent effect of some flocculant.

modified PAM flocculant by simultaneous formation method. The optimum conditions were obtained through orthogonal experiments. When making the nano-modified PAM flocculant prepared under the optimum conditions to treat the high-density waste drilling mud, the water content in filter cake is $24.32 \%$ which was significantly better than that of the other coagulant in market.

\section{Acknowledgements}

The authors gratefully acknowledge the financial supports from National Hi-Tech Research and Development Program of China (863program) (2008BAC43B02).

\section{References}

[1] M. J. Yang, W. L. Liang, Q. R. Jin, et al., "Study on Comprehensive Treatment Technique about Waste Drilling Mud," Journal of Mineralogy and Petrology, in Chinese, Vol. 23, 2003, pp. 109-112.

[2] M. Amanullah and L. Yu, "Environment Friendly Fluid Loss Additives to Protect the Marine Environment from 
the Detrimental Effect of Mud Additives," Journal of Petroleum Science and Engineering, Vol. 48, No. 3-4, 2005, pp. 199-208. doi:10.1016/j.petrol.2005.06.013

[3] S. Rehan and H. Tahir, "A Fuzzy-Based Methodology for an Aggregative Environmental Risk Assessment: A Case Study of Drilling Waste," Environmental Modelling \& Software, Vol. 20, No. 1, 2005, pp. 33-46. doi:10.1016/j.envsoft.2003.12.007

[4] C. G. Street and S. E. Guigard, "Treatment of Oil-Based Drilling Waste Using Supercritical Carbon Dioxide," Journal of Canadian Petroleum Technology, Vol. 48, No. 6, 2009, pp. 26-29.

[5] J. A. Veil, "Drilling Waste Management," Journal of
Petroleum Technology, Vol. 54, 2002, pp. 50-52.

[6] M. P. Carignan, C. B. Lake and T. Menzies, "Assessment of Two Thermally Treated Drill Mud Wastes for Landfill Containment Applications," Waste Management and Research, Vol. 25, No. 5, 2007, pp. 394-401. doi: $10.1177 / 0734242 \mathrm{X} 07073652$

[7] J. G. Zhang, J. Nie and H. Deng, “An Experimental Study on the Treatment of Waste Drilling Fluid by Solid-Liquid Separation," Environmental Protection of Oil \& Gas Fields, in Chinese, Vol. 11, 2001, pp. 20-32.

[8] X. J. Guo and H. Ma, "Application and Study of High Density Drilling Fluid Technology," Drilling Fluid and Completion Fluid, in Chinese, Vol. 26, 2009, pp. 8-10. 